\section{David Haigh}

qualified as a chartered accountant with Price Waterhouse in London. David was Director of Brand Valuation at Interbrand before launching Brand Finance in 1996. He is a member of the UK Chartered Institute of Marketing and was a member of the 1998 Advertising Effectiveness Awards judging panel. He is the author of several books on brand valuation.
Keywords: brand, brand valuation, brand equity, brand economics, intangible marketing

\section{An introduction to brand equity - How to understand and appreciate brand value and the economic impact of brand investment}

\author{
David Haigh \\ Received (in revised form): 15 April 2003
}

David Haigh

Brand Finance

8 Oak Lane

London

TW1 3PA

UK

Tel: $+44(0) 2086070300$

Fax: +44 (0)20 86070301

E-mail:

enquiry@brandfinance.com

\begin{abstract}
Commodity businesses can be profitable but are reliant upon functional purchase decision making by rational consumers, making them vulnerable to competition on both price and functionality. Brands introduce emotional decision-making criteria, differentiating even commodity products like carbonated cola drinks. Brands shift the demand curve upwards and the cost curve downwards. The result is higher turnover, profit and surplus 'consumer utility'. Brand equity is a measure of the emotional reservoir which shows how far the demand curve has moved and what the future cash flows will be. Brand valuation is a snapshot of those future cash flows. This paper describes how these three concepts fit together and explains how and why they have become best practice in marketing and financial management.
\end{abstract}

\section{Introduction}

In financial terms a brand represents the pact between a consumer and a supplier, promising a secure flow of future revenues and profits to the supplier. Ultimately, what gives a successful brand its value is that it is a specifically defensible piece of legal property with an incremental stream of revenue attached to it.

The supplier's earnings are secure because strong brands create both functional and emotional barriers to competition for the consumer's loyalty. On the functional side, brands simplify recognition and selection; they facilitate split-second purchase decisions at point of purchase. Brands provide a guarantee of origin and quality; reliable consumer choices can be made in safety. On the emotional side, brands provide reassurance: 'I am a good mother because I use Pampers.' Brands satisfy associative desires: 'I am one of the in-crowd because I wear Versace.' They are aspirational: 'I am an up-and-coming executive because I drive a BMW.' Finally, they fulfil self-expressive needs: 'I am manly because I smoke Marlboro.'

An important additional benefit of strong brands is their ability to transfer established consumer loyalty to new market areas and product categories. Brand extension is a very important way of modernising, modifying or strengthening the brand, albeit with the obvious 


\section{The power of brands}

\section{Financial impact}

concomitant risks. In order for brand stretching to be effective, it is necessary that the brand attributes are as appropriate to the new extension area as to the original product or service category. This generally means that core brand attributes must be more to do with image and emotion than with function and rationality. For example, Virgin represents innovative, exciting, youthful, friendly, uncomplicated good value whatever category it is extended into; if the Virgin brand had based its appeal exclusively on functional and rational attributes it would still be stuck in the record retailing category. It is also vital to consider the reciprocal effect - the extension area itself must add back to the brand as well as receiving the benefits of the original brand's strengths.

That strong 'brand equity' does translate into better financial performance can be seen in the cola market. In blind tests Pepsi Cola consistently outperforms Coca-Cola in terms of consumer taste preference. But when Coke-branded packaging is revealed stated preference completely reverses. When otherwise identical cars, made in the same factory, are branded either VW or Seat the price and residual value profiles differ dramatically. Branding persuades consumers to behave (irrationally) emotionally, adding value to otherwise functionally identical products and services.

\section{Brand economics}

Strong brands with high 'brand equity' possess the ability to persuade people to make economic decisions based on emotional rather than rational criteria. They consequently have a profound economic impact and economic value.

Interestingly, it is sometimes argued that branding is a way for companies to 'rip off' consumers, but the following simple example demonstrates that in a free market brands create a virtuous circle of lower prices, higher profits and higher surplus 'consumer utility'. Branding consequently has a hugely beneficial effect on individual consumers, individual companies and the economy as a whole.

Brands favourably affect both the revenue and cost curves of a business. Figure 1 shows the average revenue and cost curves of a simple commodity business, and demonstrates the absolute amount of profit made in that commodity business at a unit sale price of, say, $\$ 150$. At a price of $\$ 150$ the volume of demand is 22 units, implying total revenue of $\$ 3,300$. It will be seen that the average unit cost declines as volume grows; this is because fixed costs are spread over a larger volume of production. The average cost at a volume of 22 is approximately $\$ 100$. Total cost is therefore $\$ 2,200$, creating a profit of $\$ 1,100$.

It can be seen in this simplified example that most consumers paying $\$ 150$ would have been willing to pay a price somewhere above $\$ 150$. Some would have been willing to pay as much as $\$ 200$, and the average additional amount they would have been willing to pay is $\$ 25$. The extent to which the actual price charged is below the price a consumer would have been willing to pay represents a benefit to the consumer, a surplus of 'consumer utility'. The value of total surplus consumer utility can be calculated in this case at $\$ 550$, based on 22 units at an average consumer 


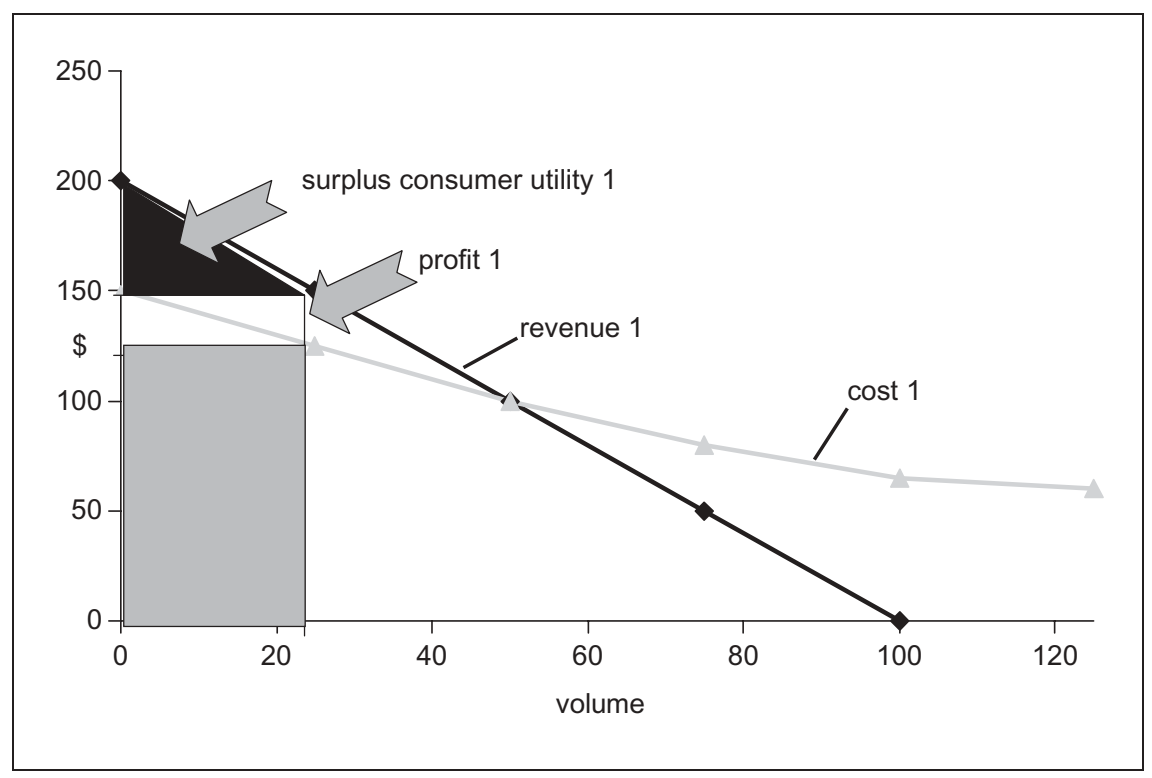

Figure 1: The Brand Finance economic model for commodity product

utility value of $\$ 25$. By contrast, a deficit of consumer utility arises if the price charged is higher than the price an individual would be happy to pay, as representing good value for money. This situation usually arises in monopoly situations or distorted supply situations.

As shown in Figure 2, if products are well branded and have acquired strong 'brand equity', the demand line moves out to the right, because consumers are quite willing to pay more. At a given price more

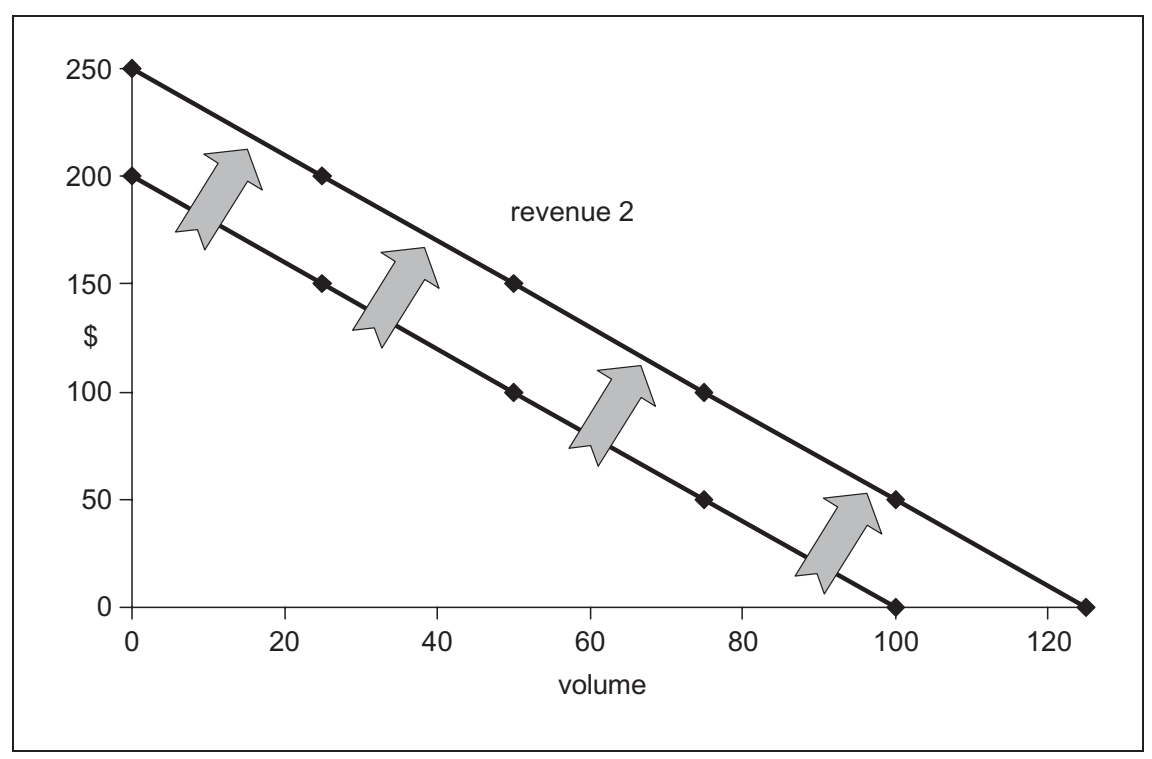

Figure 2: Strong brand equity shifts the demand curve 


\section{Emotional reactions}

\section{Branded business versus unbranded business}

consumers will buy the product, or at a higher price the same number will buy. There are various effects at work causing this phenomenon: higher trial of the category and the brand, higher repeat rates, lower lapse rates, longer customer lifetimes with the product, greater share of requirements, a willingness to pay a premium and the ready acceptance of cross-selling and up-selling.

Equally importantly, strong 'brand equity' drives down the average cost curve, as noted in Figure 3. Strong brands are more willingly distributed and stocked by the trade, resulting in lower commissions, discounts and stocking fees. Staff are more willing to work at lower average salaries (eg entry-level positions at aspirational youth-orientated companies, for instance MTV or clothing companies like Diesel, pay considerably lower salaries than their more staid competitors), stay longer and feel more motivated to work efficiently. Suppliers and providers of capital are willing to accept finer margins and less favourable terms. There are also significant production economies of scale.

The net result, shown in Figure 4, is a transformation of the commodity economic model to a branded one, with the revenue curve pushed upwards and the cost curve downwards. If the company maintained its unit sales price at $\$ 150$ it would now achieve unit sales of 45 , revenues of $\$ 6,750$, costs of $\$ 3,375$ (45 units at an average cost of $\$ 75$, down from $\$ 100$ in the commodity example) and profits of $\$ 3,375-310$ per cent of the commodity scenario. It will also produce surplus 'consumer utility' of $\$ 2,250$ (45 units at an average consumer utility of $\$ 50)-410$ per cent of the commodity scenario. Average surplus consumer utility has doubled because preference for the brand expressed in financial terms has increased significantly. Some consumers would now be willing to pay $\$ 250$ rather than the earlier maximum of $\$ 200$. Holding the price at $\$ 150$

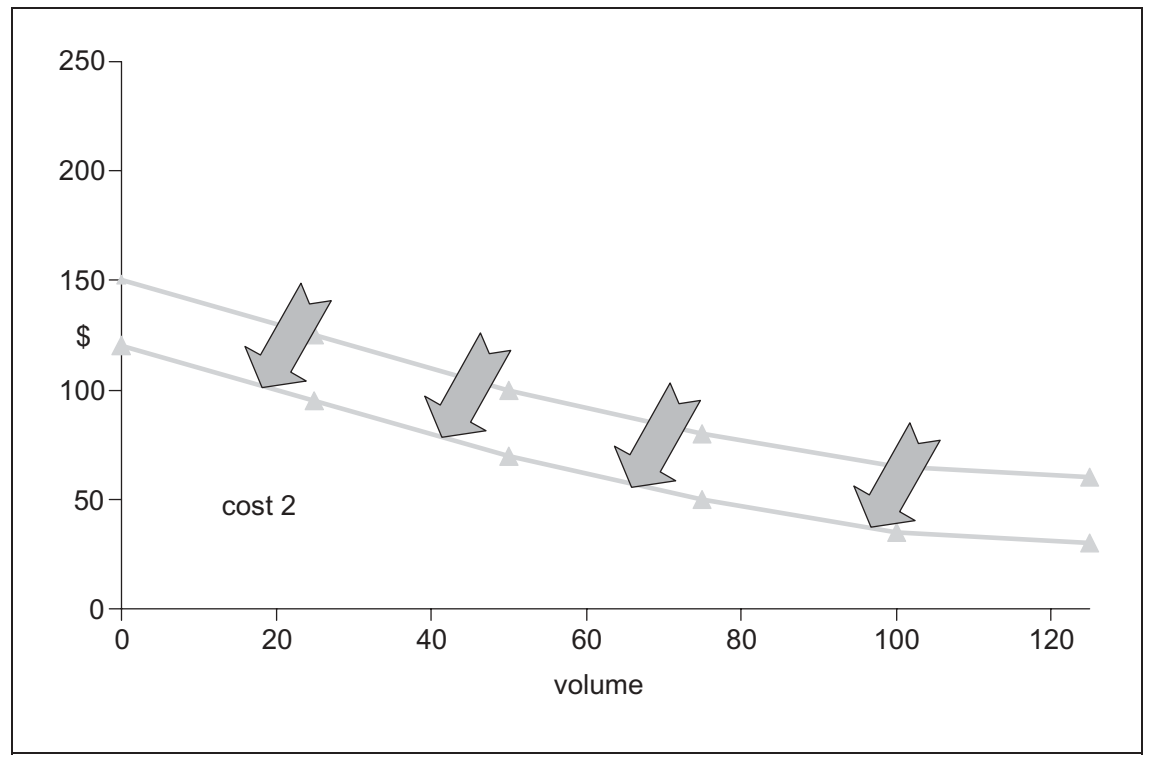

Figure 3: Strong brand equity shifts the cost curve Source: Brand Finance 


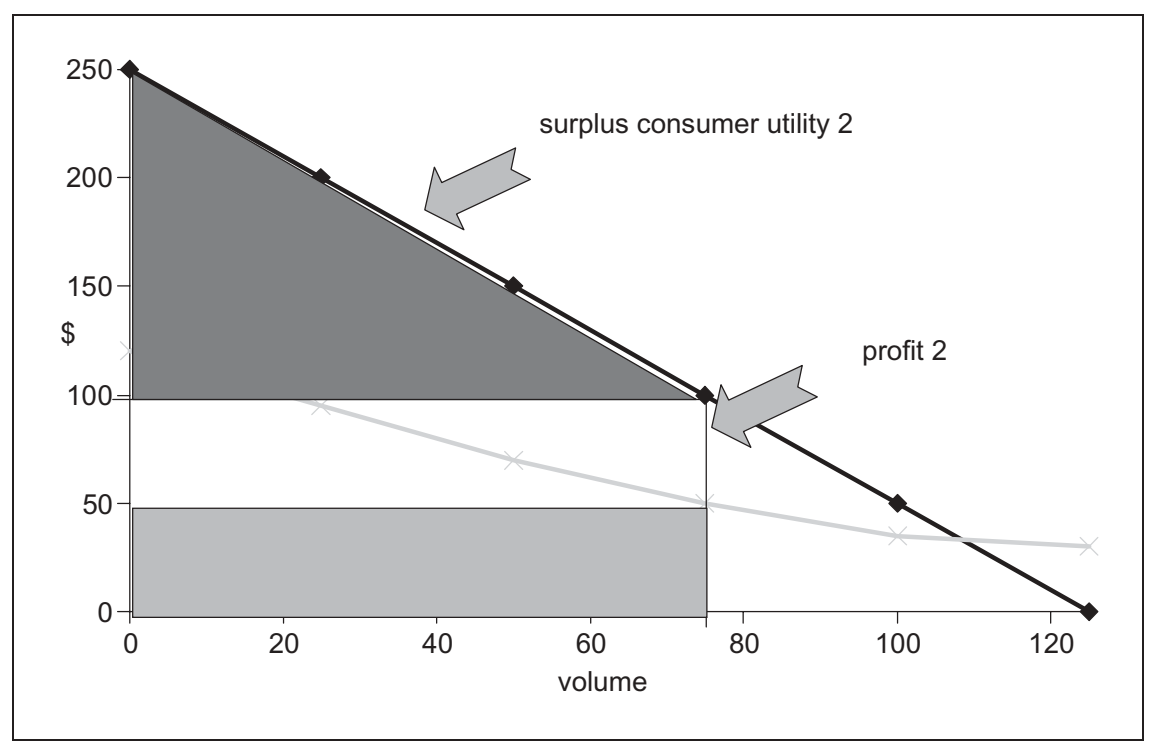

Figure 4: The Brand Finance economic model for power brand

provides greater consumer satisfaction or surplus 'consumer utility' to all consumers.

Some brand owners would be happy to leave the model at that, satisfied that they had achieved higher sales, profits and consumer utility at the original price point.

\section{Brand economics' impact on corporate strategy}

A number of interesting strategic options become available under a strongly branded business model, however.

In a commodity business an increase in price quite rationally leads to a proportionate decrease in demand, and vice versa. Volume of demand is negatively correlated to changes in price. If the correlation is perfect then the price elasticity coefficient is minus one - a perfect negative correlation. For every unit increase in price there is a unit decrease in volume demanded. The demand curve in this simplified model is a straight line of this kind.

Brand loyalty

But in a branded business demand varies in irrational ways. Demand curves are often asymmetrical and elasticity coefficients are seldom a perfect minus one. As price rises the volume of demand from brand-loyal consumers often decreases less than proportionately with the increase in price. In other words demand is inelastic with a coefficient of less than minus one. As the price falls the volume of demand from loyal consumers may increase more than proportionately because consumers seek to consume or stockpile their favourite brand at what is seen to be a highly favourable price. In this case the elasticity coefficient may be more than minus one. The shape of a branded demand curve is often ' $\mathrm{S}$ ' shaped; flattened at both ends.

In some instances brand demand curves vary in apparently irrational ways. For example, in luxury goods, demand often rises rather than falls as price rises. In extreme cases there may even be a positive rather than a 
Impact on corporate strategy

\section{Definition of brand equity}

negative correlation between volume of demand and price. Perfect positive correlation of plus one implies that for every unit increase in price there will be a unit increase in demand volume. With Bulgari jewels or Versace clothes as prices rise demand also rises; as prices fall demand also falls. Some people are prepared to pay a premium for exclusivity. Buying the psychological benefits of being one of the elite is more important than the functional benefits of owning high-quality luxury goods.

The shape of a brand's demand curve, and the exact elasticity coefficients, need to be carefully investigated before deciding on the optimal brand strategy. In the simplified example shown in Figure 4 demand increases proportionately with price decreases - there is a perfect negative correlation of minus one between price and volume of demand. In the real world this is unlikely to happen for the reasons noted above. If the brand is a strong one, then the demand line often flattens and extends as prices fall. But the example clearly demonstrates the virtuous circle created by brands like Swatch, Mars or McDonalds.

If in Figure 4 the original price is reduced by 33 per cent to $\$ 100$, volume of demand rises from 45 to 75 units, giving total revenue of $\$ 7,500-230$ per cent of Figure 1 revenues. But at this volume of demand average unit costs decline from $\$ 75$ to $\$ 50$ per unit. Total costs are therefore only $\$ 3,750$, giving a profit of $\$ 3,750-350$ per cent of Figure 1 profits. Meanwhile, surplus 'consumer utility' has increased to $\$ 5,625$ (calculated as average consumer utility of $\$ 75$ times 75 units) 1,070 per cent of Figure 1 surplus 'consumer utility'.

In other words the brand owner is working harder to provide more branded product to more consumers. The brand owner is making more profit but simultaneously creating greater consumer satisfaction and utility. Given these numbers it actually looks as though consumers receive greater incremental benefit than brand owners from the model. This is why branding in a free enterprise economy is far from being a consumer 'rip-off'. If it were, consumers would simply stop buying branded products.

The simplified economic model noted above is the model adopted by Swatch when it revolutionised the wristwatch market and has been adopted by many other enlightened brand owners. By building strong brands they kill several birds with one stone, achieving greater turnover and profit, more competitive pricing to keep out competition and significantly more satisfied, loyal consumers.

\section{Understanding how 'brand equity' drives brand economics}

'Equity' is a financial term that has been adopted by marketing people to reflect the fact that the brands they manage are financial assets which create significant shareholder value.

It reflects a growing recognition that responsibility for brands must be shared between the finance and marketing functions. The marketing department will always have responsibility for the creative aspects of brand building, maintenance and support. But as brands grow in importance, measuring, monitoring and maximising brand economics 


\section{Brand equity analysis}

effects and returns on brand investment are increasingly a shared responsibility with the finance function.

But while 'brand equity' is often talked about it is seldom clearly defined. How it works to impact on brand economics not clearly understood. Tim Ambler, of the London Business School, defines 'brand equity' as a marketing asset 'between the ears' of consumers, trade customers, staff and other stakeholders which stimulates long-term demand, cash flow and value. ${ }^{1}$

He uses the analogy of a reservoir that needs to be topped up if the outflow of water is to be maintained at a constant or increasing rate. If the 'brand equity' reservoir is depleted revenues and cash flows may remain strong for a period, but eventually the reservoir empties and cash flows dry up. A great visual analogy, but one needs really to understand the flow process.

Paul Feldwick, planning director of BMP, points out that the term 'brand equity' is often used indiscriminately to describe different points along the stream. ${ }^{2}$

\section{Consumer images, associations and beliefs}

These are high up the flow towards the source. A brand may be described as 'young', 'green' or 'exciting'. It is possible to measure and report how such brand images, associations and beliefs vary from consumer group to consumer group, how they change from time to time and how they affect purchase decisions. This provides great diagnostic insight into the consumer segments around which a financial brand valuation is structured.

\section{Consumer brand strength or loyalty}

These intermediate outputs may be measured in terms of attitudes or awareness, price elasticity, demand volume and purchase frequency. There are many different ways of tracking 'brand strength'. Econometric modelling of empirical data, experimental trade-off analysis and 'share of category requirements' analysis are just a few of the techniques available. Such measures help forecast future cash flows used in a financial brand valuation.

\section{Financial brand value}

Brand valuations are a snapshot of future brand earnings taken at a point in time. They reflect the sustainable outflow and put a firm financial value on it. They depend on an accurate prediction of future brand health because they are based on forecast cash flows generated by the brand. They rely on an accurate estimate of the future flow, which the reservoir has yet to produce. The flow rate may be falling or rising depending on the amount of 'brand equity' left in the reservoir.

\section{Brand Finance's definition of 'brand equity'}

\section{Brand equity measurement systems}

\section{'Brand equity' measures 'the propensity of specific audiences to express} preferences which are financially favourable to the brand'. Brand equity measurement systems isolate and analyse the attributes that explain 


\section{Points within the 'flow'}

\section{Brand scorecards}

changes in this propensity and predict future financial behaviour. Brand equity helps explain the shape of demand and cost curves in a brand economics study.

Figure 5 illustrates how the flow referred to by Tim Ambler ${ }^{3}$ works in practice and how the measures referred to by Feldwick ${ }^{4}$ fit together in determining the rate of that flow.

In determining the brand's value at a point in time one considers the current and future financial performance - the expected flow rate from the reservoir. The output measure that allows one to value the brand is ultimately the volume and value of sales generated by the brand.

Volumes and values can be explained and predicted by consumer behavioural measures such as trial and repeat purchase rates, or willingness to pay a price premium. These are determined by brand preference.

Moving back up the flow, one can see that brand preference is driven by a mixture of functional attributes (such as perceived product quality, value for money or convenience of distribution) and by image attributes (such as status, ethics or association with the brand).

Brand preference is affected to different degrees by different attributes. Typically, one uses conjoint or trade-off analysis to understand the weight of these attributes on preference and brand choice. These intermediate measures are really the predictive heart of a 'brand equity' measurement framework. They allow one to measure and understand how the flow rate will change in the future.

For example, in the case of a retail fuel client a balanced scorecard of individual perceptual attribute measures has been correlated, together with stated brand preference, against relative volume share in over 100 countries. Changes in the composite brand index scores are closely correlated with changes in volume share, as shown in Figure 6. This curve can be used for predicting likely volume share changes as marketing actions are taken to improve or deteriorate individual brand attributes and brand preference - making it a very powerful planning tool.

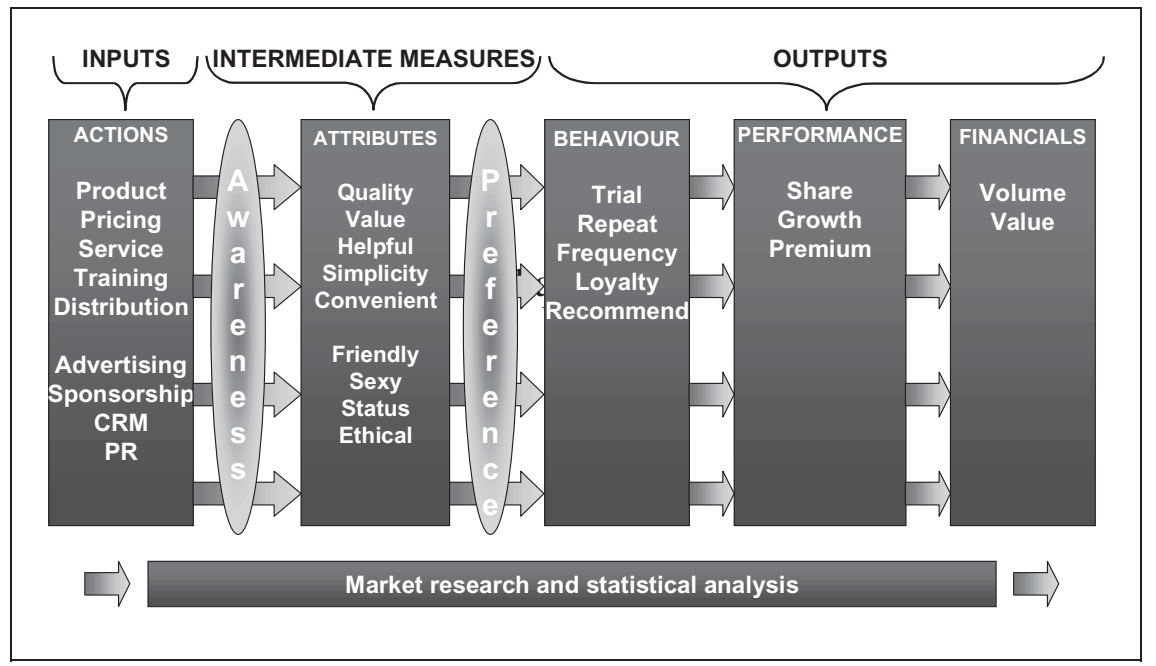

Figure 5: Linking brand equity to value drivers Source: Brand Finance 


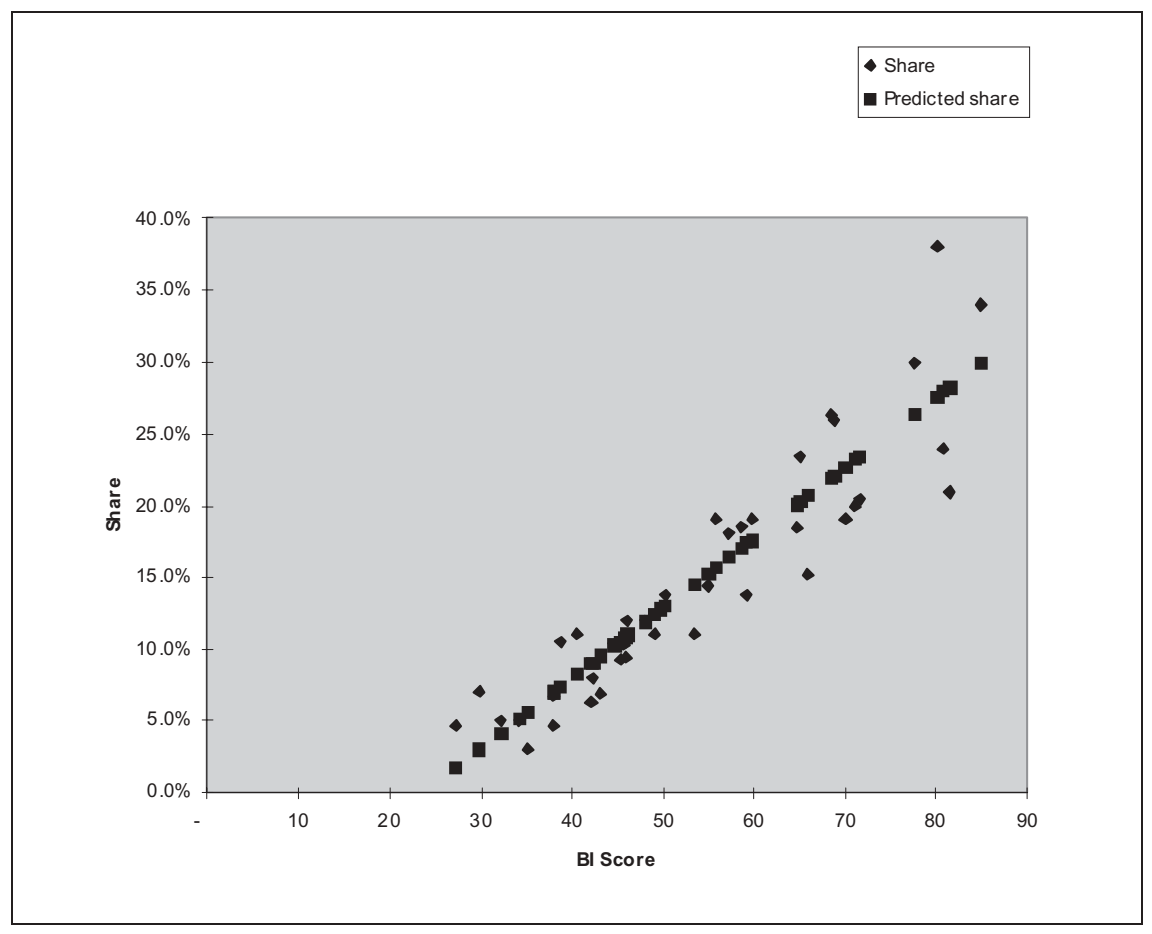

Figure 6: Brand equity index versus volume share Source: Brand Finance

\section{Brand valuation framework}

At the source of the 'brand equity' flow are the inputs or direct actions which can be taken by brand owners to affect the perceptions and preferences further downstream. By understanding which perceptual attributes affect brand preference most, and by understanding which actions have the greatest impact on the perceptual attributes, the brand owner is able to decide where to allocate resources to impact on the brand economics curves and maximise brand value.

Should resources be applied to functional changes, like service or product improvement? Or to marketing communications, shifting image attributes?

Brand valuation allows the brand management team to take the brand equity process and give a financial value to the flows coming from it. By creating a segmented brand valuation model it is then possible to understand where the greatest value is being created and help make those decisions at the source of the flow as to where resources will be best deployed.

Figure 7 illustrates the framework of a typical brand valuation. One first conducts a market review to understand all the trends driving the size, growth and profitability of the market within which the brand operates. One then reviews the competitors and conducts brand strength assessments.

A critical part of this process is understanding how 'brand equity' affects the brand economics and it is important to ensure that one fully understands the shape of the demand curves in each of the segments. Critically, the valuation is segmented into discrete pieces to allow an understanding of the brand contribution by segment. This reflects the fact 


\section{Segmentation of a brand}

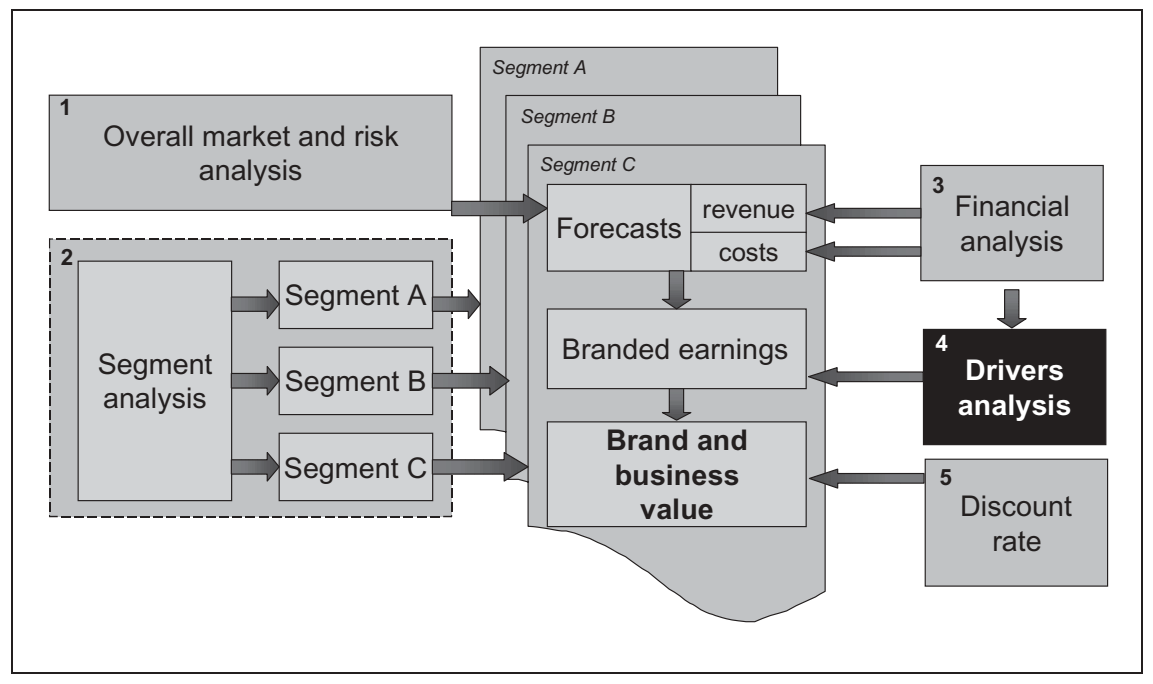

Figure 7: Brand valuation framework Source: Brand Finance

that demand conditions vary significantly from one geographic or consumer segment to another.

Next, review the internal landscape, understanding current and forecast cost structures, including how the brand affects the shape and direction of the costs curve.

So a brand valuation provides a framework for valuing the brand into segments (by geography, product, channel or consumer demographic) which matches with the analysis of 'brand equity' and underlying brand economics. By understanding 'brand equity' in aggregate and for the individual segments one is able to diagnose better how and where future value can be maximised.

Figure 8 illustrates how the flows described can be turned into a brand scorecard. The purpose of a brand scorecard is to record the input, the intermediate and the output measures along the flow. They allow managers to measure and report actions taken, perceptual attribute changes, developments on awareness and preference, behavioural measures, their impact on volumes and values and finally the financial value that all this implies. If this is reported regularly to the management and the board it provides a framework for decision making and corrective action.

Figure 9 provides an example of a typical scorecard, picking out some key measures for management reporting. Such a scorecard is provided for each key brand and segment or market in which the key brands operate. It is a summary, and behind the headlines there is usually a wealth of data kept in a relational database for enquiry once a problem or opportunity has been spotted.

There is no simple measure of 'brand equity'. There are several measures which, taken together, inform management decision making. What major companies are beginning to realise is that all of the measures available need to be gathered, reviewed and prioritised in a structured brand audit and considered as a whole in the brand evaluation process. 


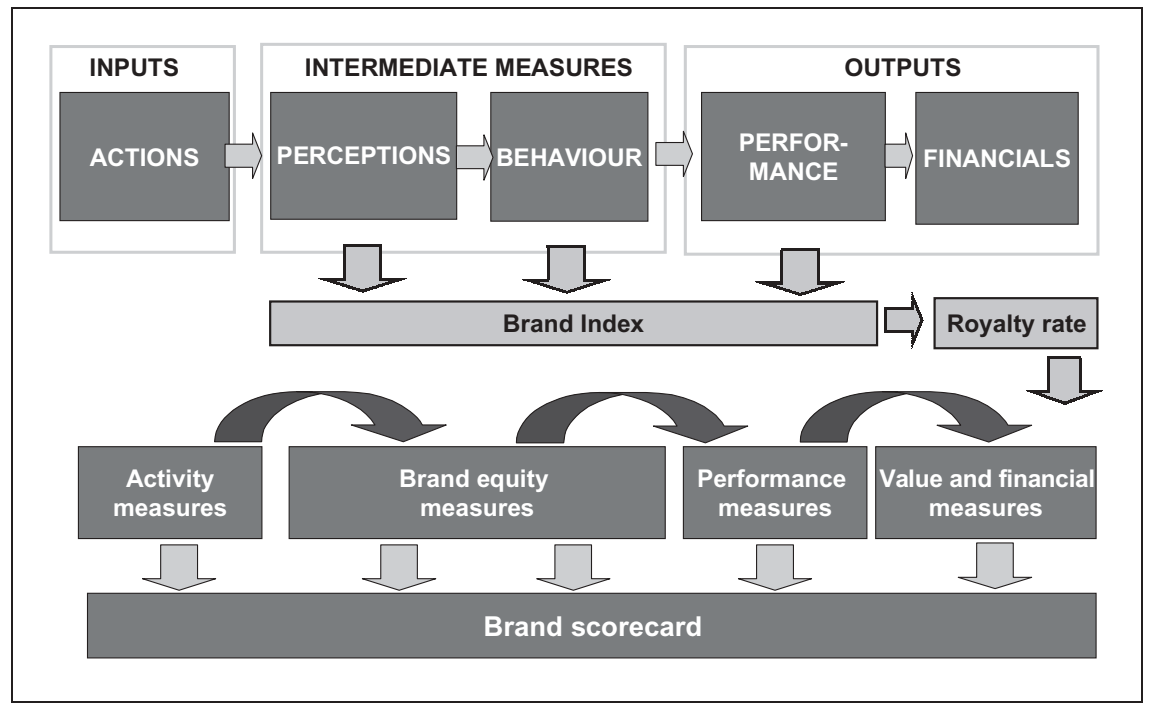

Figure 8: Building a brand scorecard Source: Brand Finance

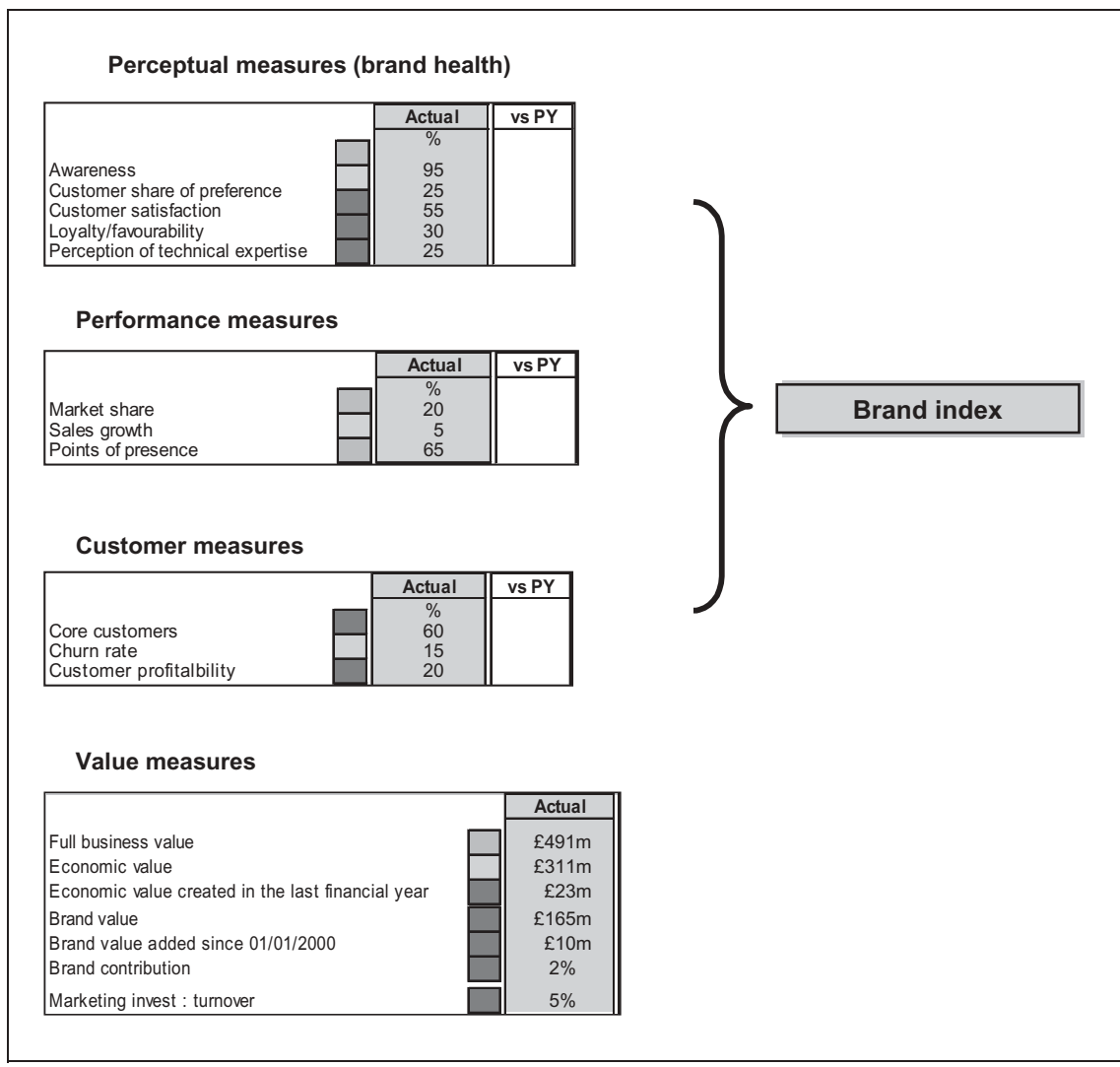

Figure 9: Typical brand scorecard 


\section{Future of brand valuation}

Ideally data should be statistically analysed to find persuasive if not definitive relationships which can be tested empirically.

To this end more and more companies are building brand monitoring and forecasting systems with large volumes of detailed research and financial data incorporating brand equity and brand value measures.

\section{Conclusion}

Brands will be major drivers of corporate value in the 21 st century. Investors and business leaders have recognised this. Financial managers and planners are increasingly using brand equity tracking models to facilitate business planning. They should go one step further. Investors need and want greater disclosure of brand values and marketing performance. They want to understand the brand economics of individual brands better to understand the future performance and value of companies they are investing in. Financial managers should play a lead role in ensuring that such information is adequately communicated to investors, rather than waiting for statutory disclosure requirements to catch up with reality.

Having detailed information on the brand, not just a brand value in financial terms, including information on perceptual, performance and customer measures, can aid the investor relations function. By utilising detailed 'brand equity' and brand economics trackers it is possible to show the investment community the contribution of the brand as well as its actual value.

Other key areas in which a greater understanding of 'brand equity' and brand economics aids company performance include the setting of marketing budgets, resource allocation, internal communication and brand performance tracking.

Many organisations suffer from a surplus rather than a lack of market and consumer information. Unfortunately, much of this is gathered and stored in isolation. The old functional boundaries of a bygone era still prevent the effective flow and integration of information. Even if brand tracking data make it on to the intranet or a shared directory, they tend to remain in 'research speak' and tend not to be used by financial and strategic planners.

What marketers and brand owners need to ensure is that adequate data are collected centrally and regularly, that relationships between the data variables are understood, that the financial value of the brand is understood and that it is monitored. It is now best practice to have a 'brand equity', brand economics and brand value reporting system of this kind, and demands for such reporting systems will be further driven by the financial and investment communities in the coming years.

\section{References}

1. Ambler, T. (2001) 'Where does cash flow from? Assessing marketing performance', paper presented to the Australian Marketing Institute National Conference, Sydney, 11 October.

2. Feldwick, P. (1998) ESOMAR Handbook of Market and Opinion Research, ESOMAR Publications, Amsterdam.

3. Ambler, ref. 1 above.

4. Feldwick, ref. 2 above. 